\title{
LA SUSPENSIÓN DEL CONTRATO DE TRABAJO POR NACIMIENTO: ¿HACIA UNA EFECTIVA CORRESPONSABILIDAD?
}

\author{
The suspension of the employment contract due to birth: \\ towards an effective co-responsibility?

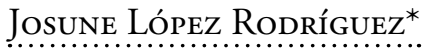 \\ Universidad de Deusto, España
}

\begin{abstract}
RESUMEN
La finalidad de este trabajo radica en analizar, desde un punto de vista crítico, la configuración actual de la suspensión del contrato de trabajo por nacimiento tras la reforma operada por el Real Decreto-Ley 6/2019, de 1 de marzo, de medidas urgentes para garantía de la igualdad de trato y de oportunidades entre mujeres y hombres en el empleo y la ocupación. Así, mediante este análisis crítico, se pretende verificar si la regulación de esta modalidad de suspensión del contrato en el ordenamiento jurídico-laboral interno resulta adecuada para garantizar una corresponsabilidad efectiva en el ámbito familiar. A tal fin, en primer lugar, se realiza una breve aproximación conceptual a la corresponsabilidad, diferenciándola de la noción clásica de conciliación; en segundo lugar, se explica el fundamento de esta modalidad de suspensión; en tercer lugar, se presenta su evolución en el ordenamiento jurídico español desde la década de los 80 ; y, en cuarto lugar, se analiza y valora su alcance actual.
\end{abstract}

Palabras clave: suspensión del contrato; nacimiento; corresponsabilidad; Real Decreto-Ley 6/2019

\section{ABSTRACT}

The aim of this paper is to analyse, from a critical point of view, the current configuration of the suspension of the employment contract due to birth after the reform operated by Royal Decree Law 6/2019, of March 1, of urgent measures to guarantee equal treatment and opportunities between women and men in employment and occupation. Therefore, by means of this critical analysis, we will try to verify if the regulation of this modality of suspension of the contract within the national labour legal system is adequate to guarantee an effective co-responsibility in the context of family. To that end, first, we will make a brief conceptual approach to co-responsibility, differentiating it from the classic notion of conciliation; secondly, we will explain the basis for this type of suspension; thirdly, we will present its evolution in the Spanish legal system since the 80s; and, lastly, we will analyse and evaluate its current scope.

Keywords: suspension of the contract; birth; co-responsibility; Royal Decree Law 6/2019.

\footnotetext{
* Correspondencia a: Josune López Rodríguez. Facultad de Derecho. Universidad de Deusto. Avenida de las Universidades 24, Bilbao, Bizkaia (España). — josunelopezrodriguez@deusto.es — https: //orcid.org/0000-0002-3153-1547

Cómo citar: López Rodríguez, Josune. (2021). "La suspensión del contrato de trabajo por nacimiento: ¿hacia una efectiva corresponsabilidad?»; Lan Harremanak, 45, 44-78. (https: //doi.org/10.1387/lan-harremanak.22815).

Recibido: 15 mayo, 2021; aceptado: 13 junio, 2021.

ISSN 1575-7048 - eISSN 2444-5819 / (c) 2020 UPV/EHU
} 


\section{Introducción}

La efectiva corresponsabilidad en la asunción de las responsabilidades y obligaciones familiares constituye un reto social imprescindible para lograr una verdadera igualdad de género.

En efecto, tanto desde la comunidad internacional como desde la Unión Europea se pone de manifiesto la necesidad de promover el reparto equilibrado de responsabilidades en el ámbito familiar como presupuesto indispensable para lograr la igualdad de género.

En el plano internacional, la Agenda 2030 para el Desarrollo Sostenible, aprobada mediante la Resolución de la Asamblea General de las Naciones Unidas de 25 de septiembre de 2015, incluye como uno de sus objetivos «lograr la igualdad entre los géneros y empoderar a todas las mujeres y las niñas» (cfr. Objetivo 5). Más concretamente, en el marco de este Objetivo, una de las metas propuestas radica en «reconocer y valorar los cuidados y el trabajo doméstico no remunerados mediante servicios públicos, infraestructuras y políticas de protección social, y promoviendo la responsabilidad compartida en el hogar y la familia, según proceda en cada país» (cfr. Meta 5.4.). Y, en el ámbito de la Unión Europea, la Directiva (UE) 2019/1158 del Parlamento Europeo y del Consejo, de 20 de junio de 2019, relativa a la conciliación de la vida familiar y la vida profesional de los progenitores y los cuidadores, y por la que se deroga la Directiva 2010/18/UE del Consejo ${ }^{1}$, determina que «las políticas de conciliación de la vida familiar y la vida profesional deben contribuir a lograr la igualdad de género promoviendo [entre otras cuestiones] el reparto igualitario de las responsabilidades en el cuidado de familiares entre hombres y mujeres» (cfr. Considerando sexto).

Partiendo de estas premisas, en el marco jurídico-laboral, una de las medidas que pueden favorecer la consecución de esta corresponsabilidad familiar es, sin duda, la suspensión del contrato de trabajo por nacimiento.

De este modo, el presente trabajo tiene por objeto analizar, desde una perspectiva crítica, la configuración actual de la suspensión del contrato de trabajo por nacimiento en el ordenamiento jurídico-laboral interno tras la aprobación y entrada en vigor del Real Decreto-Ley 6/2019, de 1 de marzo, de medidas urgentes para garantía de la igualdad de trato y de oportunidades entre mujeres y hombres en el empleo y la ocupación ${ }^{2}$, con el fin último de verificar si la regulación del mismo resulta adecuada para garantizar una corresponsabilidad efectiva en el ámbito familiar.

\footnotetext{
1 DOUE de 12 de julio de 2019, L 188.

2 BOE de 7 de marzo de 2017, núm. 57.
} 
A tal fin, en primer lugar, se realizará una breve aproximación conceptual a la corresponsabilidad, diferenciándola de la noción clásica de conciliación; en segundo lugar, se explicará el fundamento en el que se basa la suspensión del contrato de trabajo por nacimiento; en tercer lugar, a modo de contextualización, se expondrá su evolución a partir de la década de los años 80; y, en cuarto y último lugar, se analizará su alcance actual.

\section{De la concepción clásica de la conciliación hacia una efectiva corresponsabilidad}

La incorporación de la mujer al mundo del trabajo ha conllevado numerosos cambios y retos para conciliar el trabajo fuera y dentro del hogar familiar y superar, de esta forma, la tradicional división de roles asignados a las mujeres y a los hombres (Moreno Gené, 2020: 24).

En el marco jurídico interno, la Constitución española no se refiere expresamente a la conciliación de la vida personal, familiar y laboral. Sin embargo, el texto constitucional «proporciona herramientas suficientes para proteger los derechos de conciliación» (Quintanilla Navarro, 2017: 348). Así, la conciliación guarda relación, por un lado, con los principios de igualdad y no discriminación, reconocidos en el artículo 14, y, por otro lado, con el mandato del artículo 39 orientado a la protección de la familia y la infancia ${ }^{3}$. De este modo, puede decirse que la conciliación de la vida personal, familiar y laboral es «un bien jurídicamente protegido a nivel constitucional» (Cámara Botía, 2012: 104).

Sobre la base de esta fundamentación, se elaboró la Ley 29/1999, de 5 de noviembre, para promover la conciliación de la vida familiar y laboral de las personas trabajadoras ${ }^{4}$, con el fin de configurar un sistema que contemplase las nuevas relaciones sociales y el reparto equilibrado de las responsabilidades en la vida profesional y en la privada. A partir de este momento, el término "conciliación» se integró de forma sólida en el ordenamiento jurídico interno y ha sido objeto de una evolución normativa mediante la cual se han ido disponiendo distintos medios para conjugar la vida familiar y la laboral (Gorelli Hernández, 2020: 126).

A grandes rasgos, la conciliación comprende «un conjunto de medidas normativas a través de las cuales se pretende facilitar que el trabajador pueda armonizar o coordinar el tiempo dedicado al trabajo con la atención de responsabilidades de carácter familiar o personal» (Gorelli Hernández, 2020: 126). Así, «estas medidas permiten que el trabajador pueda asumir ambas responsabilida-

\footnotetext{
3 A este respecto, vid. Sentencia del Tribunal Constitucional 26/2011, de 14 de marzo, recurso de amparo número 9145-2009, Fundamento jurídico 2.․

4 BOE de 6 de noviembre de 1999, núm. 266.
} 
des de forma que compatibilice su ejercicio sin tener que renunciar a ninguna de ellas» (Pérez Anaya, 2021: 6).

Ahora bien, la perspectiva clásica de la conciliación se ha centrado fundamentalmente en conseguir el simple equilibrio temporal entre el trabajo y las responsabilidades familiares, dejando «en el estricto espacio doméstico el reparto de responsabilidades» (Ballester Pastor, 2011: 55). Así, han sido las mujeres las que principalmente han hecho uso de estas medidas de conciliación, una realidad que las sitúa en una clara posición de desventaja en el mercado laboral y provoca, en consecuencia, su discriminación laboral indirecta (Blázquez Agudo, 2017: 5). Precisamente, en muchos casos, la regulación del derecho conciliatorio ha tenido lugar "mediante el uso de acciones positivas o de discriminación inversa de las mujeres, susceptibles de provocar, en no pocas ocasiones, el resultado contrario de perpetuación de roles, es decir, el indeseado "efecto boomerang»" (Prieto Padín, 2021: 213).

Esta concepción clásica de la conciliación, que «tenía el grave riesgo de perpetuar la asunción mayoritariamente femenina de las tareas de cuidado", evidenció la necesidad de integrar en la misma dos elementos básicos, a saber: las connotaciones de género que tienen las tareas de cuidado y la implicación de nuevos sujetos en las responsabilidades familiares (Ballester Pastor, 2011: 55-56).

Y a dicha necesidad responde, ciertamente, el término de corresponsabilidad, que se ha ido integrando en el ordenamiento jurídico tras la entrada en vigor de la Ley Orgánica 3/2007, de 22 de marzo, para la igualdad efectiva de mujeres y hombres 5 . En principio, la corresponsabilidad tiene el mismo propósito que la conciliación, esto es, compaginar el trabajo con las necesidades personales y familiares (Gorelli Hernández, 2020: 126). Ahora bien, el alcance de este término va más allá de la mera conciliación, en tanto en cuanto mediante el mismo no solamente se pretende armonizar el binomio trabajo-familia, sino que también se persigue la implicación de otros sujetos y entidades A este respecto, si bien la corresponsabilidad suele vincularse generalmente con la implicación de los hombres en las tareas de cuidado, lo cierto es que en el ámbito jurídicolaboral este término implica también a otros sujetos, a saber: a todos los miembros de la unidad familiar, al empresario y a la sociedad (Ballester Pastor, 2011: 56). En último término, la corresponsabilidad persigue un reparto equitativo de las responsabilidades familiares que produzca una efectiva situación de igualdad, «exigencia que no solo debe ser jurídica, sino ante todo ética y social» (Gorelli Hernández, 2020: 126).

Así las cosas, "la corresponsabilidad de hombres y mujeres en la atención a la familia ha de ser el fundamento de las políticas legislativas que abordan este

5 BOE de 23 de marzo de 2007, núm. 71. 
tema dentro de un modelo social que se ha de basar en la igualdad de trato y oportunidades» (López López, 2002: 68). Es decir, la corresponsabilidad familiar «se ha de abordar desde claves de igualdad de derechos de hombres y mujeres» (Rodríguez Escanciano, 2005: 55).

\section{Fundamento de la suspensión del contrato de trabajo por nacimiento}

En virtud del artículo 45.2 del Real Decreto Legislativo 2/2015, de 23 de octubre, por el que se aprueba el texto refundido de la Ley del Estatuto de los Trabajadores (en adelante, TRLET) ${ }^{6}$, la suspensión del contrato de trabajo «exonera de las obligaciones recíprocas de trabajar y remunerar el trabajo». Dicho de otro modo, la suspensión conlleva la «cesación temporal de las prestaciones básicas de ambas partes de la relación jurídica» (Montoya Melga, 2018: 440). Como consecuencia de ello, en principio, la suspensión del contrato de trabajo también conlleva la suspensión de la obligación de cotizar a la Seguridad Social. No obstante, a modo de excepción, el legislador protege especialmente a determinados sujetos cuyo contrato de trabajo se encuentra suspendido, estableciendo la obligación de cotizar en dichos casos - entre ellos se encuentra, concretamente, el nacimiento y cuidado del menor- (Arrieta Idiakez, 2019: 309).

El fundamento de esta figura radica en reforzar la estabilidad en el empleo de los trabajadores, evitando la extinción del contrato de trabajo ante la aparición de una circunstancia obstativa y conservando, así, el negocio jurídico (Montoya Melgar, 2018: 441). De esta manera, cuando el contrato de trabajo se suspende, el mismo sigue vigente —es decir, no se extingue-, de tal forma que, según el artículo 48.1 del TRLET, «al cesar las causas legales de suspensión, el trabajador tendrá derecho a la reincorporación al puesto de trabajo».

Pues bien, en el apartado primero del artículo 45 del TRLET, se enumeran las causas que pueden conducir a la suspensión del contrato de trabajo. Entre las mismas se encuentra, ciertamente, el

nacimiento, adopción, guarda con fines de adopción o acogimiento, de conformidad con el Código Civil o las leyes civiles de las Comunidades Autónomas que lo regulen, siempre que su duración no sea inferior a un año, de menores de seis ańos o de menores de edad mayores de seis ańos con discapacidad o que por sus circunstancias y experiencias personales o por provenir del extranjero, tengan especiales dificultades de inserción social y familiar debidamente acreditadas por los servicios sociales competentes [cfr. apartado d)].

${ }^{6}$ BOE de 24 de octubre de 2015, núm. 255. 
En concreto, a los efectos de esta investigación, se prestará atención a la causa de suspensión del contrato de trabajo por nacimiento de hijo/a. Sin embargo, es importante tener presente que el ordenamiento jurídico-laboral no se limita a proteger los casos de parto o alumbramiento, sino que también abarca supuestos como el de la adopción o acogimiento, aunque en el presente trabajo no se profundizará en los mismos. Incluso, debe tenerse en consideración la evolución de la idea tradicional de familia y su impacto en el ordenamiento jurídico, como ha quedado patente con el debate jurídico surgido en torno a la maternidad subrogada y la protección social (Llorens Espada, 2017: 138-147 y Mercader Uguina, 2017: 454-466).

Antes de entrar en materia, conviene aclarar cuándo se entiende que se ha producido la situación protegida, esto es, el nacimiento de hijo/a. De conformidad con el párrafo primero del artículo 48.4 del TRLET, el nacimiento, en lo que a la suspensión del contrato se refiere, "comprende el parto y el cuidado de menor de doce meses». Por consiguiente, «el concepto de nacimiento en el actual marco legislativo no se circunscribe al momento del parto o alumbramiento, sino que se extiende durante los doce primeros meses de vida del menor» 7 .

Al hilo de esta cuestión, y de conformidad con el artículo 30 del Código Civil $^{8}$, debe tenerse presente que «la personalidad se adquiere en el momento del nacimiento con vida, una vez producido el entero desprendimiento del seno materno». Con base en esta disposición, dos son los requisitos que deben cumplirse, a saber: la vitalidad en el momento del nacimiento y el entero desprendimiento del seno materno (Fernández Collados, 2018: 502). En el supuesto de fallecimiento del hijo o la hija después del parto, el periodo de suspensión no se ve reducido, salvo que, una vez finalizadas las seis semanas de descanso obligatorio, se solicite la reincorporación al puesto de trabajo ( $c f r$. artículo 48.4 del TRLET).

Ahora bien, ¿qué ocurre si el fallecimiento del feto se produce antes del nacimiento? En estos casos, la madre conserva el derecho a la suspensión del contrato de trabajo por maternidad, siempre que el feto hubiera permanecido en el seno materno, al menos, ciento ochenta días ( $c f r$. artículo 8.4 del Real Decreto 295/2009, de 6 de marzo, por el que se regulan las prestaciones económicas del Sistema de la Seguridad Social por maternidad, paternidad, riesgo durante el embarazo y riesgo durante la lactancia ${ }^{9}$ ), "frontera temporal criticada en la doctrina por dificultar el acceso a la prestación incongruentemente» (Llorens Espada, 2017: 132). Sin embargo, si el hijo o la hija fallece antes del inicio de la

\footnotetext{
7 Sentencia de la Sala de lo Social de la Audiencia Nacional 22/2020, de 21 de febrero de 2020, número de recurso 275/2019, Fundamento jurídico 3. ${ }^{\circ}$.

8 Gaceta de Madrid de 25 de julio de 1889, núm. 206.

9 BOE de 21 de marzo de 2009, núm. 69.
} 
suspensión o permiso del padre, no se reconoce el subsidio por paternidad ( $c f r$. artículo 26.7 del Real Decreto 295/2009).

Respecto de este último apunte, los tribunales han manifestado opiniones contrapuestas. Así, la Sala de lo Social del Tribunal Superior de Justicia del País Vasco, ha reconocido el derecho del otro progenitor distinto de la madre biológica a suspender el contrato de trabajo, aunque no se cumplan los requisitos del artículo 30 del Código Civil ${ }^{10}$. Precisamente, entiende el Tribunal que el citado precepto del Código Civil «tiene por finalidad regular los derechos de las personas una vez nacidas» $y$, por ende, dicha norma no resulta aplicable al objeto de debate ${ }^{11}$. Así, el Tribunal considera que el permiso de paternidad no tiene como finalidad exclusiva el cuidado del hijo o hija, sino que su fin es más amplio y también abarca la nueva situación familiar, por lo que la necesidad del permiso por paternidad puede ser evidente en los casos de fallecimiento, al igual que la situación paralela de maternidad —esta última reconocida legalmente-, en un contexto en el que "hay un sufrimiento claro por parte de la madre y del padre» ${ }^{12}$. En contraposición a este posicionamiento, la Sala de lo Social del Tribunal Superior de Justicia de Aragón explica que el permiso de maternidad y paternidad atienden a dos realidades diferentes y que cuando se produce el fallecimiento del feto antes del nacimiento, el permiso de paternidad carece de situación que lo fundamente, porque su finalidad no es la que justifica el permiso de maternidad $^{13}$. Así, argumenta el Tribunal que, al haber fallecido el feto antes de nacer, no existe una nueva realidad familiar a la que atender y no se dan nuevas responsabilidades que deba asumir el padre ${ }^{14}$.

\section{Evolución: de la suspensión del contrato de trabajo por maternidad y paternidad a la suspensión del contrato de trabajo por nacimiento}

En el ordenamiento jurídico español, la Ley 8/1980, de 10 de marzo, del Estatuto de los Trabajadores ${ }^{15}$, reconocía la maternidad de la mujer trabajadora como causa de suspensión del contrato de trabajo [cfr. artículo 45.1.d)]. En concreto, se determinaba que, en el supuesto de parto, la suspensión del contrato tendría una duración máxima de catorce semanas, distribuidas a la opción de la interesada ( $c f r$. artículo 48.4). Respecto de esta —insuficiente- inicial re-

\footnotetext{
10 Sentencia del Tribunal Superior de Justicia del País Vasco 1123/2019, de 29 de mayo de 2018, número de recurso 982/2018.

11 Fundamento jurídico $3 .^{\circ}$.

12 Ídem.

13 Sentencia del Tribunal Superior de Justicia de Aragón 50/2019, de 30 de enero de 2019, número de recurso 819/2018.

14 Fundamento jurídico $4^{\circ}$.

15 BOE de 14 de marzo de 1980, núm. 64.
} 
gulación, cabe destacar que no se recogió expresamente el descanso obligatorio durante las primeras seis semanas posteriores al parto, obviando, de esta forma, el mandato establecido en el artículo 3.3 del Convenio 103 de la Organización Internacional del Trabajo sobre la protección de la maternidad, de 1952, ratificado por España en $1966^{16}$, en virtud del cual «la duración del descanso tomado obligatoriamente después del parto será fijada por la legislación nacional, pero en ningún caso será inferior a seis semanas". Además, en relación con la situación del otro progenitor distinto de la madre biológica, la norma se limitó a reconocerle el derecho, previo aviso y justificación, a ausentarse de su puesto de trabajo con derecho a remuneración durante dos días en los casos de nacimiento de hijo/a y durante cuatro días cuando el trabajador necesitara hacer un desplazamiento a tal efecto [cfr. artículo 37.3.b)].

Con el fin de suplir los vacíos de la Ley 8/1980, pocos ańos después, la Ley 3/1989, de 3 de marzo, por la que se amplía a dieciséis semanas el permiso por maternidad y se establecen medidas para favorecer la igualdad de trato de la mujer en el trabajo ${ }^{17}$, modificó el artículo 48.4 de la citada norma, estableciendo que en el caso de parto, la suspensión del contrato de trabajo de la madre biológica tendría una duración de dieciséis semanas ininterrumpidas, ampliables por parto múltiple hasta dieciocho semanas. Igualmente, se determinó que, si bien la distribución del periodo de suspensión dependía de la interesada, seis semanas debían disfrutarse inmediatamente después del parto, pudiendo hacer uso de las mismas el otro progenitor en caso de fallecimiento de la madre. Mediante este último requerimiento, relativo al disfrute de seis semanas inmediatamente después del parto, se dio cumplimiento al mandato internacional emanado de la Organización Internacional del Trabajo. El establecimiento de un periodo de seis semanas posteriores al parto tenía por objeto, principalmente, la recuperación de la madre, mientras que el resto del periodo estaba orientado, sobre todo, al cuidado del/a hijo/a en sus primeros meses de vida (Pérez Guardo y Serrano Serrano, 2013: 44). Además, con respecto a los supuestos en los que los dos progenitores trabajasen, se contempló la posibilidad de que la madre biológica, al iniciarse el periodo de descanso por maternidad, optara por que el otro progenitor disfrutase de hasta cuatro semanas de las últimas semanas de suspensión, siempre que fueran ininterrumpidas y al final del periodo, salvo que en el momento de su efectividad la incorporación de la madre al trabajo supusiera riesgo para su salud.

Por su parte, el Real Decreto Legislativo 1/1995, de 24 de marzo, por el que se aprueba el texto refundido de la Ley del Estatuto de los Trabajadores ${ }^{18}$, no introdujo novedades en materia de corresponsabilidad y se limitó a contemplar

\footnotetext{
16 BOE de 31 de agosto de 1966, núm. 208.

17 BOE de 8 de marzo de 1989 , núm. 57.

18 BOE de 29 de marzo de 1995, núm. 75.
} 
lo que las normas previas habían delimitado. Así, el texto normativo reconoció, por un lado, el permiso retribuido de dos días por nacimiento de hijo/a en su artículo 37.3.b) y, por otro lado, la maternidad de la mujer trabajadora como causa de suspensión del contrato de trabajo [cfr. artículo 45.1.d)].

La Ley 39/1999, de 5 de noviembre, para promover la conciliación de la vida familiar y laboral de las personas trabajadoras ${ }^{19}$, únicamente señaló que, en el caso de que los dos progenitores trabajasen, la madre, al iniciarse el periodo de dieciséis semanas, podía optar por que el otro progenitor disfrutara de una parte determinada e ininterrumpida del mismo (excepto las primeras seis semanas posteriores al parto) de manera simultánea o sucesiva con el de la madre, salvo que en el momento de su efectividad la incorporación al trabajo de la madre pudiera suponer un riesgo para su salud.

Claramente, estas primeras normas se centraron en la protección de la maternidad y no recogieron medidas concretas orientadas a favorecer la conciliación de la vida personal, familiar y laboral y a fomentar la corresponsabilidad en el seno familiar. En este contexto, la suspensión del contrato de trabajo por maternidad estaba configurada "pensando en un modelo familiar en que la mujer [era] la responsable exclusiva de las responsabilidades domésticas y familiares» (Ballester Pastor, 2011: 65).

Así las cosas, en España, fue la Ley Orgánica 3/2007, de 22 de marzo, para la igualdad efectiva de mujeres y hombres, la norma que contempló, por vez primera, el permiso de paternidad -o del otro progenitor- de los trabajadores por cuenta ajena, del que deriva una prestación contributiva temporal o subsidio (Fernández Collados, 2018: 499). En el Preámbulo de la norma, el legislador avanzaba que el reconocimiento de este permiso constituía «la medida más innovadora para favorecer la conciliación de la vida personal, familiar y laboral».

En virtud del artículo 44.3) la Ley Orgánica 3/2007, de 22 de marzo, se reconoció al otro progenitor distinto de la madre biológica el derecho a un permiso individual, exclusivo e intransferible y a una prestación, en los términos previstos en la normativa laboral y de Seguridad Social, ello en aras de contribuir a un reparto más equilibrado de las responsabilidades familiares (Cordero Gordillo, 2019: 7). También se incluyeron mejoras en el periodo de suspensión del contrato de trabajo por maternidad, ampliándolo en dos semanas para los casos de hijo/a con discapacidad, pudiendo hacer uso de dicha ampliación indistintamente ambos progenitores.

A partir del mandato incluido en el apartado once de la disposición adicional décimo primera de esta norma, se introdujo en el entonces vigente Real Decreto Legislativo 1/1995, de 24 de marzo, un nuevo precepto, el 48 bis, para

19 BOE de 6 de noviembre de 1999, núm. 266. 
regular la suspensión del contrato de trabajo por paternidad, eso sí, «de modo notablemente rígido" (Ballester Pastor, 2011: 65). En concreto, según el citado artículo, se reconocía el derecho - de carácter voluntario ${ }^{20}$ - a la suspensión del contrato de trabajo durante trece días ininterrumpidos al trabajador en los supuestos de nacimiento, adopción o acogimiento, periodo ampliable en el caso de parto, adopción o acogimiento múltiples en dos días más por cada hijo a partir del segundo. Al respecto, se matizó que dicha suspensión era independiente del disfrute compartido de los periodos de descanso por maternidad. Y, al mismo tiempo, se puntualizó que, en el caso de parto, el ejercicio del derecho correspondía exclusivamente al otro progenitor. Esto es, el permiso de paternidad debía disfrutarlo en exclusiva el otro progenitor distinto de la madre biológica, quien no podía cederlo a la madre (Castellano Burguillo, 2007: 221 y Molina Navarrete, 2009: 52). Más aún, el precepto estableció un periodo temporal concreto de inicio del ejercicio del derecho, a saber, desde la finalización del permiso por nacimiento de hijo/a, previsto legal —artículo 37.3.b) — o convencionalmente. De este modo,

la relación entre el permiso retribuido de «dos días por el nacimiento de hijo» [...] y la nueva causa de suspensión del contrato de trabajo por paternidad [...] era, así, muy clara: primero se disfrutaba del permiso de dos días [...] y, una vez que este finalizaba, comenzaba el periodo de suspensión de trece días del contrato de trabajo por paternidad ${ }^{21}$.

Pues bien, la diferente duración de la suspensión del contrato por paternidad (trece días) respecto de la suspensión por maternidad (dieciséis semanas), «explica que se mantuviera el permiso retribuido de dos días por el nacimiento de hijo, permiso que se sumaba - y relacionaba - con la suspensión del contrato por paternidad $» 22$. Ciertamente, se trata de «derechos de distinta naturaleza, ya que uno [radica en] disfrutar de un permiso retribuido a cargo del empresario", mientras que el otro,

que no es de nuevo cuño, [consiste en] una mera suspensión del contrato de trabajo, sin obligación retributiva para el empresario y, en cambio, con cobertura prestacional por el sistema público de Seguridad Social (que no actúa en los permisos retribuidos $)^{23}$.

20 Sobre esta cuestión, pueden consultarse las sentencias de la Sala de lo Social del Tribunal Superior de Justicia del País Vasco 2162/2008, de 23 de septiembre de 2008, número de recurso 1780/2008, Fundamento jurídico 2. ${ }^{\circ}$ y de la Sala de lo Social del Tribunal Superior de Justicia de Andalucía 2673/2010, de 5 de octubre de 2010, número de recurso 2485/2010, Fundamento jurídico 2. .

21 Sentencia de la Sala de lo Social del Tribunal Supremo 98/2021, de 27 de enero de 2021, número de recurso 188/2019, Fundamento jurídico 3. ${ }^{\circ}$, apartado 3.

22 Ibidem, Fundamento jurídico $4 .^{\circ}$, apartado 1.

23 Sentencia de la Sala de lo Social de la Audiencia Nacional 140/2019, de 29 de noviembre de 2019, número de recurso 221/2019, Fundamento jurídico 5.․ 
Con esto, el nuevo artículo 48 bis dispuso que la suspensión del contrato por paternidad podía disfrutarse bien en régimen de jornada completa bien en régimen de jornada parcial de un mínimo del cincuenta por cien, previo acuerdo entre el empresario y la persona trabajadora, y de conformidad con lo establecido reglamentariamente.

Si bien es indudable que este primer reconocimiento de la suspensión del contrato de trabajo por paternidad fue loable, lo cierto es que la duración inicial contemplada, esto es, de trece días ininterrumpidos — ampliables en los supuestos de parto, adopción o acogimiento múltiples-, resultó ser manifiestamente insuficiente para conseguir la finalidad para la cual fue concebido (Castellano Burguillo, 2007: 212 y López Aniorte, 2019: 7). Puede decirse, incluso, que el propio legislador fue consciente de este problemático aspecto temporal, al instar al Gobierno en la disposición transitoria novena de la Ley Orgánica 3/2007 a la ampliación progresiva y gradual de la duración del permiso de paternidad hasta alcanzar el objetivo de las cuatro semanas a los seis años de su entrada en vigor (Moreno Gené, 2020: 39). Además, se considera que, en aras de fomentar de manera eficaz la corresponsabilidad en el cuidado de los hijos, "debería haberse integrado [...] el permiso por nacimiento de hijo dentro del permiso por paternidad, fijándose un único permiso» (Gala Durán, 2017: 64-65).

El mandato recogido en la disposición transitoria novena de la Ley Orgánica 3/2007, de 22 de marzo, se concretó en la Ley 9/2009, de 6 de octubre, de ampliación de la duración del permiso de paternidad en los casos de nacimiento, adopción o acogida ${ }^{24}$. Antes de la entrada en vigor de la citada norma, resulta interesante puntualizar que la Ley 2/2008, de 23 de diciembre, de Presupuestos Generales del Estado para el año 2009²5, amplió en su disposición adicional sexta la suspensión del contrato de trabajo por paternidad en familias numerosas. En concreto, en la misma se determinó que dicha suspensión pasaría a tener una duración de veinte días cuando el nuevo nacimiento, adopción o acogimiento se produjera en una familia numerosa, cuando la familia adquiriera dicha condición con el nuevo nacimiento, adopción o acogimiento o cuando en la familia hubiera una persona con discapacidad, duración que quedaría ampliada en el caso de parto, adopción o acogimiento múltiple en dos días más por cada hijo/a a partir del segundo, o si uno de ellos fuera una persona con discapacidad.

El Preámbulo de la Ley 9/2009, de 6 de octubre, planteó la ampliación del periodo de paternidad exclusivo para el otro progenitor distinto de la madre biológica a cuatro semanas, con el fin de «incentivar la implicación de los hombres en las responsabilidades familiares». Esta norma no modificó, sin embargo, el momento temporal de inicio de la causa de suspensión del contrato

\footnotetext{
24 BOE de 7 de octubre de 2009, núm. 242.

25 BOE de 24 de diciembre de 2008, núm. 309.
} 
de trabajo por paternidad. Por ende, las cuatro semanas «se seguirían disfrutando «desde la finalización del permiso por nacimiento de hijo, previsto legal o convencionalmentem ${ }^{26}$.

A pesar de que la disposición final segunda de la Ley determinaba que la misma debía entrar en vigor a partir del 1 de enero de 2011, «la situación de crisis económica propició que diversas normas fueran aplazando su entrada en vigor, lo que finalmente se produjo el 1 de enero de 2017» (Cordero Gordillo, 2019: 15)27. Estos continuos aplazamientos supusieron un claro obstáculo e impedimento para la consecución de la finalidad perseguida con la norma, a saber, fomentar la igualdad efectiva de hombres y mujeres en el ámbito laboral. Precisamente, el coste económico que suponía el periodo de paternidad, a cargo del Sistema público de la Seguridad Social, prevaleció sobre el papel del mismo como incentivo de la corresponsabilidad familiar (Gala Durán, 2017: 61). Así, este lapso temporal evidenció

que la corresponsabilidad (y en general las políticas de igualdad) son consideradas una especie de lujo del que es necesario prescindir en épocas de crisis en lugar de una inversión para el sostenimiento del sistema de Seguridad Social (Ballester Pastor, 2011: 75).

El TRLET, de 23 de octubre de 2015, en su versión original, no amplió el periodo de la suspensión del contrato de trabajo por paternidad. Así, el artículo 48.7 recogió el derecho del trabajador a la suspensión del contrato por paternidad durante cuatro semanas ininterrumpidas, ampliables en los supuestos de parto múltiple en dos días más por cada hijo/a a partir del segundo. Además, se mantuvo la previsión relativa al periodo de disfrute de tal derecho, a saber, desde la finalización del permiso por nacimiento de hijo, previsto legal o convencionalmente ${ }^{28}$.

Por su parte, la disposición final trigésima octava de la Ley 6/2018, de 3 de julio, de Presupuestos Generales del Estado para el año 2018 ${ }^{29}$, amplió el periodo de la suspensión del contrato de trabajo por paternidad de cuatro a cinco semanas, ampliables en los supuestos de parto, adopción, guarda con fines de adopción o acogimiento múltiples en dos días más por cada hijo/a a partir del segundo. A pesar de esta ampliación, la regulación seguía sin garantizar la efectiva corresponsabilidad entre los dos progenitores (López Aniorte, 2019: 7).

En este contexto, y respecto de la finalidad de la suspensión del contrato de trabajo por maternidad y paternidad en los supuestos de nacimiento, el Tribu-

26 Sentencia de la Sala de lo Social del Tribunal Supremo 98/2021, de 27 de enero de 2021, número de recurso 188/2019, Fundamento jurídico 3..$^{\circ}$, apartado 3.

27 Véase la disposición adicional undécima de la Ley 48/2015, de 29 de abril, de Presupuestos Generales del Estado para el año 2016 (BOE de 30 de octubre de 2015, núm. 260).

28 Sentencia de la Sala de lo Social del Tribunal Supremo 98/2021, de 27 de enero de 2021, número de recurso 188/2019, Fundamento jurídico 3. ${ }^{\circ}$, apartado 4.

29 BOE de 4 de julio de 2018, núm. 161. 
nal Constitucional ha venido defendiendo que las razones que motivan una y otra son diferentes, de ahí que el Tribunal hubiera avalado la diferente duración prevista hasta ese momento de la suspensión del contrato de trabajo por maternidad y paternidad (Moreno Gené, 2020: 41 y Moreno Solana, 2019: 285). Así, según el Tribunal Constitucional, mientras el principal objetivo de la suspensión del contrato por paternidad introducida por la Ley Orgánica 3/2007 radicaba en favorecer la conciliación de la vida personal, familiar y laboral, ello en aras de fomentar la corresponsabilidad en el cuidado de los hijos, la suspensión del contrato por maternidad tenía por objeto proteger la salud de la mujer trabajadora, así como «la lactancia natural y la especial relación de afectividad entre la madre y el neonato» ${ }^{30}$. Sobre esta base, el Tribunal defendió en su Sentencia 111/2018, de 17 de octubre de 2018, recurso de amparo número 4344-2017, que

siendo diferentes las situaciones que se traen en comparación, no puede reputarse como lesiva del derecho a la igualdad ante la ley [artículo 14 de la Constitución] la diferente duración de los permisos por maternidad o paternidad y de las correspondientes prestaciones de la Seguridad Social ${ }^{31}$.

Ahora bien, a este último respecto, resulta de sumo interés traer a colación el Voto Particular emitido por la magistrada Dońa María Luisa Balaguer Callejón, en el que apuntó que el Tribunal había perdido la oportunidad

de diferenciar, de forma clara, entre los objetivos y finalidades con proyección constitucional asociados a las medidas de protección del hecho biológico de la maternidad - en conexión con los artículos 15 y $43 \mathrm{CE}$-, y las finalidades, con igual cabida constitucional, asociadas tanto a la garantía de igualdad de trato en el mercado laboral —artículos 14 y 35.1 CE-, como al desarrollo de medidas de conciliación de la vida laboral y personal —artículo $18 \mathrm{CE}$ - que deben ser proyectadas, sin ninguna diferencia, a los hombres y a las mujeres que tienen descendencia, a riesgo de convertirse, de no ser así, en medidas generadoras de discriminación indirecta ${ }^{32}$.

En concreto, señaló la magistrada que

ni la finalidad exclusiva del permiso de maternidad es la recuperación física de la madre, ni la finalidad del de paternidad es (solo) la conciliación, sino la garantía de la igualdad en el acceso, promoción y desarrollo de la actividad laboral de hombres y mujeres».

30 Sentencia del Tribunal Constitucional 75/2011, de 19 de mayo de 2011, cuestión de inconstitucionalidad 3515-2005, Fundamento jurídico 8. ${ }^{\circ}$. Asimismo, consúltense las Sentencias del Tribunal Constitucional 111/2018, de 17 de octubre de 2018, recurso de amparo número 4344-2017, Fundamentos jurídicos $5 .^{\circ}$ y $7 .^{\circ}$; y $2 / 2019$, de 14 de enero de 2019 , recurso de amparo número 3082018, Fundamento jurídico $4 .^{\circ}$.

31 Fundamento jurídico $7 .^{\circ}$.

32 Apartado 3. 


\section{Precisamente, añadió la magistrada que se trata de}

repartir entre el padre y la madre [los progenitores] el coste laboral que la decisión de tener descendencia tiene en las personas, de modo tal que dicha decisión impacte por igual, en el sentido que sea (positivo o negativo) tanto en el hombre como en la mujer ${ }^{33}$.

\section{En todo caso, el Tribunal Constitucional reconoció que}

es notorio que existe un prolongado debate social y político sobre la conveniencia de ampliar la duración del permiso por paternidad (y la prestación de la Seguridad Social correspondiente), incluso hasta su equiparación con el permiso por maternidad ${ }^{34}$

al tiempo que consideró que

el legislador, en el legítimo ejercicio de su libertad de configuración del sistema de Seguridad Social, apreciando las circunstancias socioeconómicas concurrentes en cada momento a la hora de administrar recursos económicos limitados para atender a un gran número de necesidades sociales [...], [puede] ampliar la duración del permiso de paternidad ${ }^{35}$.

Por su parte, el Tribunal Supremo defendió —en un supuesto en el que se reconoce la prestación por maternidad a un trabajador que es el padre biológico mediante contrato de gestación por sustitución- que la

actual regulación legal [...] no es tan cerrada como para impedir su interpretación en el sentido más favorable a los objetivos constitucionales de protección al menor, con independencia de su filiación, y de conciliación de vida familiar y laboral ${ }^{36}$.

Es decir, alejándose del criterio mantenido por el Tribunal Constitucional, el Tribunal Supremo reconoció que, mediante la protección de maternidad, se persiguen los fines constitucionales tanto de protección del menor como de conciliación de la vida familiar y laboral (López Aniorte, 2019: 8).

A partir de lo expuesto, la introducción — si bien tardía — de la suspensión del contrato de trabajo por paternidad en la legislación española debe valorarse de manera positiva como medida orientada a promover y favorecer la corresponsabilidad en la asunción de responsabilidades familiares. Ciertamente, debe tenerse en cuenta que el

\footnotetext{
33 Apartado 4.

34 Sentencia del Tribunal Constitucional 2/2019, de 14 de enero de 2019, recurso de amparo número 308-2018, Fundamento jurídico segundo.

35 Sentencia del Tribunal Constitucional 111/2018, de 17 de octubre de 2018, recurso de amparo número 4344-2017, Fundamento jurídico $8 .^{\circ}$.

36 Sentencia de la Sala de lo Social del Tribunal Supremo 881/2016, de 25 de octubre de 2016, número de recurso 3818/2015, Fundamento jurídico $10 .^{\circ}$.
} 
objetivo de mayor participación de los [progenitores no gestantes] en el cuidado de sus menores propicia la verdadera conciliación de las responsabilidades familiares y laborales desde la perspectiva de la igualdad de género ${ }^{37}$.

En este sentido, se percibe en la evolución normativa expuesta

una tendencia a la bilateralización de la tutela mediante el reconocimiento a la madre o al padre de la posibilidad de disfrutar de los derechos sociolaborales [...] encaminados a facilitar el cuidado de los hijos y la referida búsqueda de la conciliación de la vida familiar y laboral orientada a fomentar la corresponsabilidad (Monereo Pérez y López Insua, 2016: 8).

Sin perjuicio de esta primera impresión, la exigua duración y el modesto alcance de esta suspensión, así como su carácter potestativo o voluntario, pusieron de manifiesto que su configuración no resultaba suficiente para lograr, de manera efectiva, el objetivo de la corresponsabilidad (Cordero Gordillo, 2019: 16; Ispizua Dorna, 2018: 581; Llorens Espada, 2017: 148; Moreno Gené, 2020: 69).

Ante este escenario, recientemente, el Real Decreto-Ley 6/2019, de 1 de marzo, ha equiparado la duración del derecho de suspensión del contrato de trabajo por nacimiento de los dos progenitores que, desde enero de 2021, es de dieciséis semanas. Tal y como se explica en la Exposición de Motivos, esta equiparación responde "a la existencia de una clara voluntad y demanda social» ${ }^{38} \mathrm{y}$, con la misma,

se da un paso importante en la consecución de la igualdad real y efectiva entre hombres y mujeres, en la promoción de la conciliación de la vida personal y familiar, y en el principio de corresponsabilidad entre ambos progenitores, elementos ambos esenciales para el cumplimiento del principio de igualdad de trato y de oportunidades entre hombres y mujeres en todos los ámbitos.

De este modo, el Real Decreto-Ley 6/2019 ha reconocido

un derecho subjetivo, individual y exclusivo del otro progenitor a la suspensión del contrato de trabajo tanto en supuestos de paternidad biológica, como también en los supuestos de adopción, guarda con fines de adopción o acogimiento de un menor (Moreno Gené, 2020: 69-70).

Sin duda alguna, esta equiparación

37 Sentencia de la Sala de lo Social del Tribunal Superior de Justicia del País Vasco 2420/2017, de 11 de diciembre de 2017, número de recurso 2168/2017, Fundamento jurídico $3 .^{\circ}$.

38 Sobre esta cuestión, pueden consultarse las sentencias de la Sala de lo Social de la Audiencia Nacional, de 29 de noviembre de 2019, número de recurso 221/2019, Fundamento jurídico 4. ${ }^{\circ}$, y de 21 de febrero de 2020, número de recurso 275/2019, Fundamento jurídico 3.. 
constituye un paso necesario, aunque no suficiente, para evitar que las medidas de protección de la parentalidad o familia, y los efectos negativos que el mercado de trabajo les asocia, se vinculen exclusiva o principalmente a las mujeres (Pastor Martínez, 2019: 199).

Además, esta norma ha modificado el artículo 37.3.b) del TRLET, del que se ha suprimido la referencia al permiso retribuido de dos días por nacimiento de hijo/a ( $c f r$ r. artículo 2, apartado nueve). La eliminación de este permiso se basa, muy probablemente, en el hecho de que los fines perseguidos por el permiso de nacimiento han quedado comprendidos en la nueva configuración de la suspensión del contrato del otro progenitor por nacimiento de hijo/a (Moreno Gené, 2020: 38). Ahora bien, a este último respecto, ¿qué ocurre si el convenio colectivo aplicable establecía una mejora respecto de la previsión legal sobre el permiso retribuido por nacimiento?

Recientemente, la Sala de lo Social del Tribunal Supremo se ha pronunciado sobre este asunto, entendiendo que

la supresión del permiso retribuido de dos días por nacimiento de hijo, que reconocía el artículo 37.3 b) [TRLET], y la equiparación de la duración de la suspensión de contrato de trabajo de ambos progenitores, hacen inaplicable el precepto del convenio colectivo de empresa que mejoraba la previsión legal sobre aquel permiso ${ }^{39}$.

En concreto, entiende la Sala que la previsión del convenio colectivo en cuestión $^{40}$, que reconocía que el padre disponía, «además del permiso legalmente establecido", de tres días naturales contados desde la fecha en que se produzca el parto, «no es sencillo que pueda tener vida autónoma propia una vez que aquel permiso legal ha desaparecido sin haber sido sustituido por ningún otro» ${ }^{41}$. En otras palabras, explica el Tribunal que una norma sobrevenida [esto es, la modificación de los artículos 37.3.b) y 48.4 del TRLET por el Real Decreto-Ley 6/2019] implica que la disposición del convenio colectivo objeto de disputa "haya perdido sus originarias finalidad y alcance» ${ }^{42}$. Junto con este argumento, el Tribunal Supremo también sostiene que el convenio colectivo en cuestión establece un momento temporal de ejercicio del permiso retribuido de tres días por nacimiento — desde la fecha en que se produzca el parto- que «no es com-

39 Sentencia de la Sala de lo Social del Tribunal Supremo 98/2021, de 27 de enero de 2021, número de recurso 188/2019, Fundamento jurídico $4 .^{\circ}$.

40 Artículo 30 del Convenio Colectivo de empresa de Eusko Trenbideak/Ferrocarriles Vascos, S.A. [Resolución de 13 de noviembre de 2018, de la Directora de Trabajo y Seguridad Social, por la que se dispone el registro, publicación y depósito del Convenio Colectivo de la Sociedad Pública Eusko Trenbideak/Ferrocarriles Vascos, S.A., 2017-2020. (Boletín Oficial del País Vasco núm. 229 de $28 / 11 / 2018)]$.

41 Sentencia de la Sala de lo Social del Tribunal Supremo 98/2021, de 27 de enero de 2021, número de recurso 188/2019, Fundamento jurídico $4 .^{\circ}$, apartado 2.

42 Ibidem, Fundamento jurídico 4. ${ }^{\circ}$, apartado 3. 
patible ni puede conciliarse con las previsiones sobre el comienzo de la suspensión del contrato de trabajo por nacimiento» ${ }^{43}$. Es decir, teniendo en cuenta que el periodo de suspensión de seis semanas inmediatamente posteriores al parto es obligatorio, entiende el Alto Tribunal que no es posible disfrutar después de ese tiempo de los días de permiso de manera independiente (Palomino Saurina, 2021: 3). De este modo, el Tribunal Supremo confirma la sentencia recurrida, a saber, la sentencia de la Sala de lo Social del Tribunal Superior de Justicia del País Vasco 1438/2019, de 16 de julio de 2019, número de recurso 16/2019, en la que se concluía que

no puede aceptarse la vigencia en el convenio de la mejora de un derecho legal que ya no existe; ni resulta legítimo, en relación a idéntica materia y derecho, que los trabajadores pretendan acogerse a dos fuentes distintas (el convenio y la ley) ${ }^{44}$.

Resulta oportuno señalar que la citada sentencia del Tribunal Superior de Justicia del País Vasco contó con un voto particular del magistrado Don Juan Carlos Benito Butrón, en el que manifestó que

a falta de una disposición expresa derogatoria de las normas convencionales, la actual disposición derogatoria única del RDL 6/2019, solo conforma la derogación de normas de igual o inferior rango que se opongan o contradigan lo dispuesto en dicho RDL, pero no establece de forma expresa ningún tipo de derogación de las normas convencionales que mejoren o superen la consecución de los derechos tratados ${ }^{45}$.

En este sentido, argumentó el magistrado que

las normas convencionales pueden complementar, mejorar derechos básicos reglados en el [TRLET], cuya modificación o reforma, en tanto en cuanto no desborda o contradiga los derechos mejorados, deben mantenerse subsistentes los que sean beneficiosos de conformidad con lo ya negociado, atendiendo al principio de favorabilidad de sus efectos positivos, al margen de la prioridad y preferencia aplicativa jerárquica ${ }^{46}$.

Este posicionamiento coincide con la argumentación que había venido sosteniendo la Sala de lo Social de la Audiencia Nacional ${ }^{47}$, al considerar que «la finalidad del permiso [reconocido en el convenio colectivo] subsiste aún después

43 Ibidem, Fundamento jurídico $4^{\circ}$, apartado 2.

44 Sentencia de la Sala de lo Social del Tribunal Superior de Justicia del País Vasco 1438/2019, de 16 de julio de 2019, número de recurso 16/2019, Fundamento jurídico 2. ${ }^{\circ}$.

45 Voto Particular, Fundamento jurídico 3. ${ }^{\circ}$.

46 Ídem.

47 Por ejemplo, en las sentencias de la Sala de lo Social de la Audiencia Nacional 140/2019, de 29 de noviembre de 2019, número de recurso 221/2019, Fundamento jurídico 4. ${ }^{\circ} ; 22 / 2020$, de 21 de febrero de 2020, número de recurso 275/2019, Fundamento jurídico 3. ${ }^{\circ}$; y 6/2021, de 3 de febrero de 2021, número de recurso 247/2020, Fundamento jurídico 5.. 
del periodo de suspensión del contrato" ${ }^{48}$. Sin embargo, recientemente, tras la sentencia del Tribunal Supremo, la Sala de lo Social de la Audiencia Nacional ha modificado su postura, no solamente por la mayor jerarquía del Tribunal Supremo, sino también "por las convincentes razones que fundamentan su decisión ${ }^{49}$.

\section{Actual regulación de la suspensión del contrato de trabajo por nacimiento}

Tal y como se ha avanzado en el apartado anterior, el Real Decreto-Ley 6/2019, de 1 de marzo, ha equiparado la duración del derecho de los dos progenitores a la suspensión del contrato de trabajo por nacimiento, mediante la modificación del apartado 4 del artículo 48 del TRLET. Si bien la aprobación de esta norma ha sido considerada "precipitada e insuficiente", al mismo tiempo, se ha reconocido que la misma "difícilmente puede calificarse de innecesaria o banal» (Ballester Pastor, 2019: 14).

La reforma se ha llevado a cabo a través de la figura del Real Decreto-Ley que, de conformidad con el artículo 86.1 de la Constitución, requiere «extraordinaria y urgente necesidad» para su adopción por el ejecutivo. En la Exposición de Motivos de la norma se argumenta que «la mitad de la población está sufriendo una fuerte discriminación y está viendo afectados sus derechos fundamentales», lo que "exige una actuación urgente y necesaria por parte del Estado». No cabe duda que la desigualdad es una realidad incontestable que requiere la actuación de los poderes públicos; ahora bien, la desigualdad y la discriminación en el ámbito laboral por razón de sexo no son temas que hayan surgido repentinamente, sino que constituyen un problema anclado en la sociedad y en el mercado de trabajo. De ahí que pueda cuestionarse el correcto uso del Real Decreto-Ley en los términos exigidos por la Constitución (Ballester Pastor, 2019: 17).

Como paso preliminar, conviene comentar que, desde una perspectiva de terminología jurídica, uno de los aspectos novedosos introducidos a este respecto por el Real Decreto-Ley 6/2019, es el cambio en la denominación del permiso. Así, las expresiones "permiso de maternidad» y «permiso de paternidad» utilizadas por los textos jurídicos anteriormente citados pasan a denominarse "permiso por nacimiento». De este modo, el nuevo "permiso por nacimiento»

48 Sentencia de la Sala de lo Social de la Audiencia Nacional 22/2020, de 21 de febrero de 2020, número de recurso 275/2019, Fundamento jurídico 3..$^{\circ}$. Sobre esta cuestión, consúltese Molina Navarrete, 2020: 172-175.

49 Sentencia de la Sala de lo Social de la Audiencia Nacional 56/2021, de 24 de marzo de 2021, número de recurso 340/2020, Fundamento jurídico 4. ${ }^{\circ}$. 
unifica en el mismo los permisos de maternidad y paternidad (Molina González-Pumariega, 2020: 7). El principal objetivo de esta equiparación en la denominación radica en reforzar la finalidad de la corresponsabilidad, «eliminando el título por el que se ejerce (madre o padre)", de tal forma que el permiso por nacimiento surge «con relación al hecho físico del parto, constituyendo un derecho de igual configuración para la madre biológica y para el otro progenitor» (Ballester Pastor, 2019: 27). Este cambio terminológico, que en principio pudiera parecer insignificante, exige una lectura más detenida. Ciertamente, la principal finalidad de la equiparación de los anteriores permisos de maternidad y paternidad radica en fomentar el reparto de las responsabilidades familiares, de ahí que, como se verá, el permiso sea intransferible. En este sentido, la expresión «permiso por nacimiento" puede inducir a la confusión acerca de su verdadero propósito, ya que «da una falsa (o, al menos, confusa) sensación de que su función primordial es el cuidado, aunque insista en su carácter intransferible» (Ballester Pastor, 2019: 27). Además, la reforma

centra la regulación y la protección en el nacimiento y cuidado del menor y deja en un segundo plano el hecho de la maternidad biológica que, como hecho diferencial femenino, debe ser objeto de protección desde la perspectiva de la salud laboral y frente a las consecuencias negativas que para ella puede conllevar (Molina GonzálezPumariega, 2020: 8-9).

Ante este cambio de denominación, algunos autores advierten que futuros Gobiernos, no tan comprometidos con la corresponsabilidad en el seno familiar, podrían llegar a eliminar la referencia a la naturaleza intransferible del permiso al considerar que el bien principal perseguido con el mismo es el cuidado del menor (Ballester Pastor, 2019: 26; Lousada Arochena, 2019: 4; y Molina González-Pumariega, 2020: 9). Este hipotético cambio supondría, claramente, un retroceso en el camino hacia una efectiva corresponsabilidad.

Hecho este breve inciso, debe señalarse que, en virtud del apartado dieciocho del artículo 2 del mencionado texto normativo, en el caso de nacimiento, la materialización de la equiparación de los periodos de suspensión del contrato de trabajo debía producirse de manera paulatina en el caso del otro progenitor distinto de la madre biológica. Esto es, mientras la madre biológica debía disfrutar completamente de los periodos de suspensión desde su entrada en vigor - precisamente, la nueva suspensión por nacimiento se equipara a la anterior regulación de la suspensión por maternidad-, el periodo de suspensión del otro progenitor debía aplicarse de manera progresiva $-\mathrm{y}$ es que lo que se persigue es equiparar la situación del otro progenitor a la situación de la madre biológica(Gorelli Hernández, 2019: 295). Conviene matizar que la expresión «progenitor distinto de la madre biológica", que ya había venido empleándose con el permiso de paternidad, resulta acertada al ajustarse a las distintas realidades sociales y familiares existentes (Moreno Gené, 2020: 31). 
Así, primero, a partir de su entrada en vigor, el otro progenitor debía contar con un periodo de suspensión total de ocho semanas, de las cuales las dos primeras debía disfrutarlas de manera ininterrumpida inmediatamente después del parto. A este respecto, se determinó que la madre biológica podría ceder al otro progenitor un periodo de hasta cuatro semanas de su periodo de suspensión de disfrute no obligatorio. Cabe observar que, en esta primera fase transitoria, el periodo de suspensión anterior se vio incrementado en tres semanas, alcanzándose únicamente la mitad del periodo de dieciséis semanas.

Segundo, a partir del 1 de enero de 2020, el otro progenitor debía contar con un periodo de suspensión total de doce semanas, de las cuales las cuatro primeras debía disfrutarlas de forma ininterrumpida inmediatamente después del parto. En este supuesto, se contemplaba la posibilidad de que la madre biológica cediera al otro progenitor un periodo de hasta dos semanas de su periodo de suspensión de disfrute no obligatorio. En esta segunda etapa transitoria, el periodo de suspensión previo se vio aumentado en cuatro semanas, restando todavía cuatro para lograr el objetivo final de las dieciséis semanas.

Y, tercero, a partir del 1 de enero de 2021, se ha equiparado finalmente la duración de la suspensión del contrato de trabajo de la madre biológica y del otro progenitor, reconociéndose el derecho individual de cada progenitor a disfrutar de un permiso intransferible de dieciséis semanas de suspensión ${ }^{50}$. La regulación actual de la duración de la suspensión del contrato del otro progenitor como consecuencia del nacimiento "cumple con creces» el mínimo exigido para el permiso de paternidad por el artículo 4.1 de la Directiva (UE) 2019/1158, esto es, diez días laborables (Moreno Gené, 2020: 41).

Pues bien, de estas dieciséis semanas, las seis semanas ininterrumpidas inmediatamente posteriores al parto, que deben disfrutarse a jornada completa, son de carácter obligatorio para los progenitores. El artículo 48.4 especifica que, en el caso de la madre biológica, el disfrute de las seis semanas posteriores al parto de manera ininterrumpida y a jornada completa está orientado a proteger su salud, mientras que, en el supuesto del otro progenitor, la razón se fundamenta en el cumplimiento de los deberes de cuidado previstos en el artículo 68 del Código Civil, en virtud del cual los progenitores deben «compartir las responsabilidades domésticas y el cuidado y atención de ascendientes y descendientes y otras personas dependientes a su cargo». El diseño de la suspensión del contrato de trabajo del otro progenitor como «una auténtica obligación o deber del mismo, al menos, por lo que respecta a las primeras seis semanas», supone un avance indiscutible, habida cuenta de que en la regulación

${ }^{50}$ La duración actual del periodo de suspensión del contrato de trabajo por nacimiento requiere ser objeto de estudio para valorar si realmente es suficiente en aras de lograr la finalidad propuesta por el mismo. 
anterior esta suspensión se configuraba como un derecho de carácter dispositivo (Moreno Gené, 2020: 32).

Al hilo de esta última cuestión, cabe advertir que el disfrute obligatorio de seis semanas ininterrumpidas después del parto resulta lógico para la madre biológica, sobre todo, por razones de salud. Sin embargo, pueden surgir dudas acerca de la necesidad de que el otro progenitor disfrute obligatoriamente a continuación del parto de seis semanas ininterrumpidas de manera simultánea a la madre biológica y no en otro momento en el que pudiera asumir toda la responsabilidad del cuidado (Molina González-Pumariega, 2020: 12). En este sentido, esta configuración respecto del otro progenitor puede considerarse «excesivamente rígida», pudiendo haberse fijado un período inicial más corto, "lo cual además hubiera podido favorecer un eventual disfrute no simultáneo de mayor duración $y$, en consecuencia, un periodo total de cuidado del recién nacido por sus progenitores más prolongado» (Cordero Gordillo, 2019: 17-18 y Moreno Gené, 2020: 56).

Además, en relación con el establecimiento del disfrute obligatorio de las seis semanas posteriores al parto, lo cierto es que, al no contemplarse ningún mecanismo de control del ejercicio del derecho ni mecanismos de sanción en el caso de no disfrutarlas, puede resultar que, en la práctica, la medida no sea lo suficientemente incentivadora y, al final, dependa de la voluntad de los sujetos obligados (Ballester Pastor, 2019, 29 y Moreno Solana, 2019: 301). Así, esta obligación se configura "como un cierto brindis al sol, ya que una norma que establezca un deber legal de obligado cumplimiento debería tener consagrada su correspondiente sanción para el caso de incumplimiento» (Moreno Solana, 2019: 303). Más aún, es discutible que «la nota de obligatoriedad del descanso se haya limitado a las seis primeras semanas inmediatamente posteriores al parto [...] y no a todo el periodo de suspensión del contrato, es decir, las dieciséis semanas» (Moreno Gené, 2020: 34). Precisamente, el carácter voluntario de las diez semanas restantes puede llevar a algunos progenitores a reincorporarse al trabajo después de las seis primeras semanas y a rechazar el disfrute del tiempo restante, posibilidad que, evidentemente, afecta negativamente a la corresponsabilidad en la distribución de las responsabilidades familiares.

Uno de los aspectos más importantes del periodo de suspensión es su carácter intransferible, que pretende tener un impacto en el reparto equilibrado de responsabilidades familiares y evitar, así, la perpetuación de los estereotipos en relación con las tareas de cuidado ${ }^{51}$. Ciertamente, el carácter intransferible del permiso por nacimiento constituye un elemento fundamental para favorecer la corresponsabilidad, de ahí que deba valorarse positivamente.

51 Acerca de esta cuestión, pueden consultarse Alonso Bravo, 2012: 143-143; Gala Durán, 2017: 66; Nieto Rojas, 2018: 620; y Rodríguez Pastor, 2018: 656. 
En relación con este carácter intransferible del permiso por nacimiento, ¿qué ocurre en el caso de familias monoparentales? Esta cuestión resulta de sumo interés en tanto en cuanto las familias monoparentales, encabezadas en su mayoría por mujeres ${ }^{52}$, constituyen una realidad social en la que la conciliación personal, familiar y laboral suele resultar más compleja ${ }^{53}$. Pues bien, la norma no se pronuncia acerca de estos supuestos, habiendo desaprovechado el legislador la oportunidad con esta reforma de mejorar la protección de las familias monoparentales (Moreno Solana, 2019: 308). Así pues, en principio, cabe deducir que, en caso de nacimiento de hijo/a, el único progenitor tendrá derecho a la suspensión del contrato de trabajo durante dieciséis semanas en los términos explicados anteriormente, sin ninguna singularidad (Molina González-Pumariega, 2020: 23 y Moreno Gené, 2020: 51). Claramente, esta situación provoca que «el menor esté menos tiempo cuidado y atendido que aquel menor que tenga a sus dos progenitores, siempre y cuando estos no disfruten de sus permisos de forma simultánea» (Molina González-Pumariega, 2020: 12).

Ante este vacío jurídico relativo a los nuevos modelos de familia, la Sala de lo Social del Tribunal Superior de Justicia del País Vasco dictó el pasado 6 de octubre de 2020 una sentencia pionera, en la que se reconoce el derecho de la demandante, al frente de una familia monoparental, a incorporar a su prestación de dieciséis semanas las ocho semanas que hubiesen podido corresponder al otro progenitor para el caso de tratarse de una familia bilateral, con el correspondiente abono de la prestación de Seguridad Social que le hubiera correspondido al otro progenitor, ello sobre la base del principio general del interés superior del menor ${ }^{54}$.

Según el Tribunal Superior de Justicia del País Vasco, la prestación objeto de examen y la reforma introducida en el TRLET por el Real Decreto-Ley 6/2019, de 1 de marzo, «se congenia con tres vías claras: la protección del menor y en general de la infancia; la introducción de una medida de igualdad de

52 Según los datos del Instituto Nacional de Estadística, en los últimos años, las familias monoparentales han estado constituidas mayoritariamente por mujeres. Así, en el año 2020, de 1.944 .800 familias monoparentales, 1.582 .100 estaban encabezadas por mujeres y 362.700 por hombres; en el año 2019, de un total de 1.887.500 familias monoparentales, 1.530.600 estaban constituidas por mujeres y 356.900 por hombres; en el año 2018, de 1878.500 familias monoparentales, 1.538.200 estaban constituidas por mujeres y 340.300 por hombres; en el año 2017, de 1.842 .400 familias monoparentales, 1.529.900 eran familias constituidas por mujeres y 312.600 encabezadas por hombres; y, en el ańo 2016, de un total de 1.964 .900 familias monoparentales, 1.591.200 estaban constituidas por mujeres y 373.700 por hombres (Instituto Nacional de Estadística. Encuesta continua de hogares: número de hogares monoparentales según sexo, edad y estado civil del progenitor).

53 Sobre los principales problemas que padecen las familias monoparentales, vid. Gońi Sein, 2005: 16-18.

54 Sentencia de la Sala de lo Social del Tribunal Superior de Justicia del País Vasco 1217/2020, de 6 de octubre de 2020, número de recurso 941/2020, Fundamento jurídico tercero. Puede consultarse un comentario a la sentencia en Pérez Guerrero, 2021. 
la mujer; y un elemento de conciliación de la vida familiar $"{ }^{55}$. En concreto, el Tribunal estima el recurso con base en la primera de las consideraciones y, para argumentar su decisión, invoca la Convención sobre los Derechos del Niño, adoptada por la Asamblea General de las Naciones Unidas el 20 de noviembre de 1989 y ratificada por Espańa el 26 de enero de $1990^{56}$, con base en el artículo 10.2 del texto constitucional, en virtud del cual

las normas relativas a los derechos fundamentales y a las libertades que la Constitución reconoce se interpretarán de conformidad con la Declaración Universal de Derechos Humanos y los tratados y acuerdos internacionales sobre las mismas materias ratificados por España.

En primer lugar, el Tribunal aduce que, con base en la citada Convención, los Estados deben respetar los derechos enunciados en la misma, sin distinción alguna por la condición del niño, de sus padres o de sus representantes legales, debiéndose adoptar todas las medias para que el niño se vea protegido contra toda forma de discriminación o castigo por causa de la condición, las actividades, las opiniones expresadas o las creencias de sus padres, tutores o familiares (cfr. artículo 2). En segundo lugar, con base en los artículos 3 y 18 de la Convención, argumenta la Sala que todas las medidas adoptadas por las Instituciones Públicas o Tribunales deben considerar primordialmente el interés superior del niño. Y, en tercer lugar, el Tribunal recuerda que, en virtud del artículo 26 de la Convención, las prestaciones de la Seguridad Social deben reconocerse teniendo en cuenta la situación del nińo y de las personas responsables de su mantenimiento. Más aún, el Tribunal Superior de Justicia del País Vasco alude a la jurisprudencia de la Sala Cuarta del Tribunal Supremo ${ }^{57}$, en la que se aboga por la interpretación de las normas en materia de protección de la maternidad de acuerdo con el principio general del interés superior del menor que se integra en el núcleo familiar, ello de acuerdo con el artículo 8 del Convenio para la protección de los Derechos Humanos y las Libertades Fundamentales, hecho en Roma el 4 de noviembre de $1950^{58}$ — en virtud del cual toda persona tiene derecho al respeto de su vida privada y familiar-, y el artículo 39 de la Constitución española — relativo a la protección a la familia y a la infancia-. Así pues, con base en estos razonamientos, la Sala determina que si se le deniega la prestación a la beneficiaria

55 Fundamento jurídico $5 .^{\circ}$.

56 BOE de 31 de diciembre de 1990, núm. 313.

57 Entre otras, pueden verse las Sentencias de la Sala de lo Social del Tribunal Supremo $881 / 2016$, de 25 de octubre de 2016, número de recurso 3818/2015, Fundamento jurídico 9.; $953 / 2016$, de 16 de noviembre de 2016, número de recurso 3146/2014, Fundamento jurídico $10 .^{\circ} ; 1005 / 2017$, de 14 de diciembre de 2017, número de recurso 2859/2016, Fundamento jurídico $2 .^{\circ}$.

58 BOE de 10 de octubre de 1979, núm. 243. 
existe una conculcación del derecho de igualdad que consagra la Convención sobre los Derechos del Niño [...], por cuanto que la atención, cuidado y desarrollo del menor afectado va a sufrir una clara merma respecto a aquellos otros que en situación semejante, encuadrados dentro de un modelo familiar biparental, van a recibir ${ }^{59}$.

En esta misma línea, la reciente sentencia del Juzgado de lo Social de Valencia 168/2021, de 10 de mayo de 2021, avala los argumentos del Tribunal Superior de Justicia del País Vasco y reconoce a una madre, que constituye una familia monoparental, el derecho a sumar ocho semanas a su periodo de suspensión del contrato de trabajo de dieciséis semanas. En concreto, en la sentencia se explica que

la demandante no se está adueñando de ningún derecho, dado que no existe otro progenitor que tenga derecho al periodo de disfrute solicitado por la actora y, por tanto, no se trata de ninguna transferencia de su derecho individual ${ }^{60}$.

En relación con la duración del periodo que se reconoce a la demandante, la juzgadora considera que

únicamente tendría derecho [...] a las ocho semanas restantes de permiso de nacimiento y cuidado del menor, por ser éstas las que, verdaderamente, no han disfrutado ni la demandante ni el menor por el hecho de ser familia monoparental, no pudiendo ser admisible esta diferencia conforme a la normativa internacional y constitucional citada ${ }^{61}$.

Precisamente, se argumenta en la Sentencia que

debiendo haber sido disfrutadas por el otro progenitor cuatro semanas inmediatamente posteriores al parto, respecto de estas semanas no podría suscitarse una quiebra del principio de igualdad del artículo 14 de la Constitución española ${ }^{62}$.

De este modo, de las doce semanas de suspensión del contrato que hubieran correspondido al otro progenitor por nacimiento - téngase en cuenta que el nacimiento se produjo en 2020, momento en el que correspondían al otro progenitor doce semanas de suspensión del contrato de trabajo, de las cuales las cuatro primeras debían disfrutarse inmediatamente después del parto-, en la Sentencia no se reconocen a la demandante las primeras cuatro semanas, sino solamente las ocho semanas restantes.

\footnotetext{
59 Fundamento jurídico $5 .^{\circ}$.

60 Fundamento jurídico $3 .^{\circ}$.

61 Ídem.

62 Ídem.
} 
Si bien estas resoluciones no son firmes — habrá que esperar a conocer la postura del Tribunal Supremo-, pueden ser la antesala de futuros pronunciamientos en esta misma dirección e, incluso, de una futura reforma del TRLET que tenga en consideración los nuevos modelos de familia ${ }^{63}$.

Con respecto a la duración de la suspensión del contrato de trabajo por nacimiento, el artículo 48.6 del TRLET contempla dos supuestos en los que se ampliará el periodo de suspensión reconocido: por un lado, el caso de discapacidad del hijo o hija en el nacimiento; y, por otro lado, el supuesto de nacimiento múltiple, por cada hijo/a distinto del primero. La dicción literal de esta previsión puede acarrear, sin embargo, problemas interpretativos. Precisamente, en el supuesto de discapacidad del hijo o hija en el nacimiento, se establece que «la suspensión del contrato [...] tendrá una duración adicional de dos semanas», matizándose que será «una para cada uno de los progenitores». Sin embargo, en el caso de nacimiento múltiple, se dispone que procederá «igual ampliación», pero no se incluye ninguna puntualización respecto del reparto de dicha ampliación entre los dos progenitores. Esta circunstancia comporta dos posibles interpretaciones respecto de la ampliación del periodo en supuestos de nacimiento múltiple, a saber: por un lado, puede entenderse que el periodo adicional de descanso debe repartirse igual que en el caso de discapacidad del hijo o hija en el nacimiento, esto es, que a cada uno de los progenitores le corresponde una semana adicional; pero, por otro lado, cabe la posibilidad de entender que el periodo adicional, es decir, las dos semanas, puede ser disfrutado por un único progenitor (Moreno Gené, 2020: 49).

Resulta oportuno señalar que, en los casos de parto prematuro y en los supuestos en que, por cualquier otra razón, el neonato deba permanecer hospitalizado a continuación del parto, el periodo de suspensión puede computarse, a instancia de la madre biológica o del otro progenitor, a partir de la fecha del alta hospitalaria. No obstante, se excluyen de dicho cómputo las seis semanas posteriores al parto, "de suspensión obligatoria del contrato de la madre biológica» (cfr. artículo 48.4. tercer párrafo del TRLET). La literalidad de este último inciso — que solamente se refiere a la madre biológica — siembra la duda acerca de si el otro progenitor también está obligado a excluir las seis semanas posteriores al parto. Al no hacerse alusión al otro progenitor, puede entenderse que el mismo

podría reincorporarse al trabajo antes de que transcurran las seis semanas posteriores al parto y retomar posteriormente el disfrute del periodo de suspensión», interpretación que «beneficiaría además el cuidado del menor durante un periodo de tiempo más prolongado una vez reciba el alta hospitalaria (Cordero Gordillo, 2019: 19).

63 Consúltese una visión crítica sobre este tema en Molina Navarrete, 2021: 175-178. 
Además, siguiendo esta interpretación, el otro progenitor podría disfrutar, mientras tanto, del permiso reconocido en el artículo 37.5 del TRLET, en virtud del cual tendría derecho a ausentarse del trabajo durante una hora o a reducir su jornada de trabajo hasta un máximo de dos horas, con la disminución proporcional del salario en este último caso.

Asimismo, en los supuestos de parto prematuro con falta de peso y en aquellos otros casos en que el neonato precise, por alguna condición clínica, hospitalización a continuación del parto, por un periodo superior a siete días, el periodo de suspensión debe ampliarse en tantos días como el nacido se encuentre hospitalizado, eso sí, con un máximo de trece semanas adicionales. Es decir, en estos supuestos, la ampliación del periodo de duración de la suspensión queda supeditada a la concurrencia de dos requisitos: por un lado, que el recién nacido requiera hospitalización a continuación del parto, $y$, por otro lado, que esta hospitalización tenga una duración superior a siete días. Respecto de la ampliación de la suspensión del contrato en estos casos, no se recoge ninguna pauta o norma concreta de reparto del tiempo de suspensión entre los progenitores, por lo que cabe entender que se trata de un derecho individual de cada progenitor (Moreno Gené, 2020: 54).

A grandes rasgos, esta previsión encuentra su razón de ser en el hecho de que siendo el objetivo de la suspensión del contrato de trabajo proporcionar los cuidados necesarios al recién nacido y favorecer el establecimiento de las relaciones paterno-filiales, en los casos de hospitalización los cuidados son dispensados principalmente por la institución sanitaria y la compleja situación a la que se enfrentan tanto el recién nacido como los progenitores dificulta el establecimiento de las relaciones paterno-filiales, lo que lleva a ampliar la duración de la suspensión del contrato de trabajo en aras de facilitar y favorecer el estrechamiento de los vínculos familiares entre los progenitores y el recién nacido (Moreno Gené, 2020: 53-54). Respecto del alcance de esta previsión, obsérvese que el legislador se refiere expresamente a la «hospitalización a continuación del parto" y no a la "hospitalización con posterioridad al parto» (Gorelli Hernández, 2019: 290). Pues bien, una interpretación restrictiva de la expresión empleada por el legislador - hospitalización a continuación del parto-, llevaría a cuestionar el reconocimiento de estos derechos cuando la hospitalización se produjera en un momento próximo, pero con posterioridad al parto, lo que impediría, al final, la consecución de la finalidad perseguida por la nueva regulación. Por ende, conviene realizar una interpretación amplia y flexible de esta expresión (Gorelli Hernández, 2019: 290 y Moreno Gené, 2020: 53). A tal fin, puede tenerse en consideración lo establecido en el artículo 8.11 del Real Decreto 295/2009, de 6 de marzo, por el que se regulan las prestaciones económicas del sistema de la Seguridad Social por maternidad, paternidad, riesgo durante el embarazo y riesgo durante la lactancia natural ${ }^{64}$, en virtud del cual

${ }^{64}$ BOE de 21 de marzo de 2009, núm. 69. 
a efectos de la ampliación del periodo de descanso por maternidad que corresponda, [...] en los casos en que el neonato deba permanecer hospitalizado a continuación del parto, serán tenidos en cuenta los internamientos hospitalarios iniciados durante los treinta días naturales siguientes al parto.

Tras analizar los supuestos en los que se permite la ampliación del periodo de suspensión del contrato de trabajo, cabe advertir que el legislador no hace ninguna mención específica a las familias numerosas - recuérdese que la Ley 2/2008, de 23 de diciembre, contempló la ampliación del periodo de suspensión del contrato por paternidad en el caso de las familias numerosas-. Si bien es cierto que la equiparación del periodo de suspensión de ambos progenitores puede llevar a concluir que no es necesaria una ampliación del periodo en el caso de las familias numerosas, lo cierto es que

las especiales necesidades que pueden plantearse en este tipo de familias parecen justificar un tratamiento específico de las mismas en esta materia y, en consecuencia, justificarían plenamente una ampliación de la duración del periodo de suspensión del contrato de trabajo (Moreno Gené, 2020: 51).

En el caso del fallecimiento del hijo o hija, el periodo de suspensión será el mismo, esto es, no se verá reducido, salvo que, finalizadas las seis semanas de descanso obligatorio, se solicite la reincorporación al puesto de trabajo. En este supuesto, los dos progenitores pueden disfrutar la totalidad del permiso hasta el máximo de dieciséis semanas, computando, en su caso, el tiempo que hubieran disfrutado antes del fallecimiento (Lousada Arochena, 2019: 5). Cabe observar que, tras la reforma, no se recoge el supuesto de fallecimiento de la madre biológica. Se entiende que esta falta de previsión radica en la equiparación del periodo de suspensión de los dos progenitores, al mantener el progenitor distinto de la madre biológica el derecho de suspensión en su integridad (Pérez Anaya, 2021: 10).

Dicho esto, resulta oportuno comentar la estructura y la forma de disfrute de la suspensión del contrato de trabajo por nacimiento ya que, tras la reforma, la misma se configura como una suspensión fraccionable (Ballester Pastor, 2019: 27). Tal y como se ha adelantado, el nacimiento suspende el contrato de trabajo de los dos progenitores durante dieciséis semanas, de las cuales son obligatorias las seis semanas inmediatamente posteriores al parto, que deben disfrutarse de manera ininterrumpida. Ahora bien, una vez transcurridas las primeras seis semanas inmediatamente posteriores al parto, la suspensión del contrato de trabajo puede distribuirse a voluntad de los progenitores, en periodos semanales a disfrutar de forma acumulada o interrumpida y ejercitarse desde la finalización de la suspensión obligatoria posterior al parto hasta que el hijo o hija cumpla doce meses. En otras palabras, el permiso por nacimiento puede fraccionarse por semanas completas a partir de la finalización de las seis semanas inmediatamente posteriores al parto hasta que el o la menor cumpla doce meses. 
Respecto del disfrute de cada periodo semanal o, en su caso, de la acumulación de los periodos, se determina que el mismo debe comunicarse a la empresa con una antelación mínima de quince días. Este plazo de preaviso tiene como finalidad permitir a la empresa adaptar su organización a esta circunstancia. Al tratarse de una "mera obligación informativa», no cabe entender que la misma constituye una solicitud de autorización a la que el empresario pueda oponerse (Moreno Gené, 2020: 63). Sin embargo, se considera que la exigencia de un plazo de preaviso de quince días resulta excesiva si lo que realmente se pretende con el fraccionamiento del periodo de suspensión «es favorecer la adaptación del disfrute del derecho a las concretas y diferentes necesidades que puede tener cada beneficiario» (Gorelli Hernández, 2019: 288-289).

A modo de excepción, se dispone que la madre biológica puede anticipar el disfrute del permiso hasta cuatro semanas antes de la fecha prevista de parto. Esta posibilidad de anticipación no se concede al otro progenitor,

aunque no hubiera sido inoportuno concedérselo con un límite razonable $[\ldots]$ en particular si el padre se encontrase desplazado por motivos laborales, y con la finalidad precisamente de poder acompañar a la madre en el momento del parto (Lousada Arochena, 2019: 6).

Esta posibilidad de adelantamiento para la madre biológica requiere, sin embargo, una reflexión. Y es que, si la madre biológica adelanta el disfrute del permiso, se limita y recorta el periodo orientado a cuidar del hijo/a después del parto. Así, se considera que se trata esta de una "simple reminiscencia del pasado que no tiene sentido mantener» (Moreno Solana, 2019: 306) ${ }^{65}$. Precisamente, existen en la actualidad vías alternativas para acceder a la suspensión del contrato de trabajo antes del parto y mantener intacto el permiso de dieciséis semanas, ya que la necesidad de suspender el contrato de trabajo antes del parto se debe a una contingencia común o profesional, según el caso, vinculada a la necesidad de proteger la salud de la trabajadora (López Aniorte, 2000: 126; Moreno Solana, 2019: 306; Rodríguez Escanciano, 2005: 59). A este último respecto, es preciso tener en cuenta que la suspensión del contrato de trabajo por contingencias comunes supone una reducción de los ingresos, ya que la cuantía de la prestación por incapacidad temporal será del $75 \%$ de la base reguladora. Para evitar esta merma de ingresos,

se podría haber pensado en aumentar este porcentaje cuando la [incapacidad temporal] tiene por causa la situación del embarazo; o quizá se podría haber dado nueva redacción a la situación protegida del riesgo durante el embarazo (Moreno Solana, 2019: 306).

65 Sirva de ejemplo el Real Decreto Legislativo 5/2015, de 30 de octubre, por el que se aprueba el texto refundido de la Ley del Estatuto Básico del Empleado Público (BOE de 31 de octubre de 2015, núm. 261), que no contempla en su artículo 49 la posibilidad de la madre biológica de anticipar la suspensión del contrato de trabajo por nacimiento. 
Pues bien, a simple vista, esta nueva regulación, en virtud de la cual el periodo de suspensión del contrato de trabajo puede fraccionarse en semanas completas, puede parecer acertada en aras de proporcionar «mayor margen de organización a los progenitores en el cuidado y atención al menor» (Molina González-Pumariega, 2020: 17). Dicho de otro modo, la flexibilidad para disfrutar del periodo de suspensión favorece la adaptación de este derecho a las específicas necesidades personales y familiares de los progenitores (Moreno Gené, 2020: 71). Sin embargo, esta nueva configuración del periodo puede resultar problemática en la práctica, de ahí que no esté libre de críticas. Por un lado, desde la perspectiva empresarial, la posibilidad de los trabajadores de disfrutar de semanas interrumpidas a lo largo de los doce meses posteriores al nacimiento, con el preaviso de quince días, puede constituir un problema organizativo y puede llegar a tener un impacto negativo en el rendimiento de las personas trabajadoras que se acogen a este régimen. Incluso, podría suceder que algunas personas trabajadoras se pudieran ver presionadas por la empresa para acogerse a este disfrute interrumpido según las necesidades productivas de la empresa. Por otro lado, desde el punto de vista de las personas trabajadoras, el disfrute interrumpido de la suspensión podría dificultar una verdadera desconexión del trabajo, repercutiendo negativamente en la calidad del cuidado y atención a los menores de edad (Molina González-Pumariega, 2020: 17-18).

Más aún, respecto de la maternidad biológica, la nueva estructura de la suspensión colisiona con la normativa europea. Precisamente, el artículo 8.1 de la Directiva 92/85/CEE, del Consejo, del 19 de octubre de 1992, relativa a la aplicación de medidas para promover la mejora de la seguridad y de la salud en el trabajo de la trabajadora embarazada, que haya dado a luz o en periodo de lactancia (décima Directiva específica con arreglo al apartado 1 del artículo 16 de la Directiva 89/391/CEE) ${ }^{66}$, dispone que los Estados miembros deben tomar las medidas necesarias para que las trabajadoras embarazadas, las trabajadoras que hayan dado a luz y las trabajadoras en periodo de lactancia, disfruten de un permiso de maternidad de como mínimo catorce semanas ininterrumpidas, distribuidas antes y/o después del parto. En efecto, la normativa europea se refiere al disfrute ininterrumpido del permiso de maternidad, por lo que la nueva previsión del Real Decreto-Ley 6/2019, de 1 de marzo, que permite el fraccionamiento de las diez semanas restantes tras el disfrute de las primeras seis semanas después del parto, puede plantear problemas para adecuarse a la Directiva 92/85/CEE (Moreno Solana, 2019: 300 y Pastor Martínez, 2019: 201). Ciertamente, debe tenerse en consideración que esta garantía del carácter ininterrumpido del permiso de maternidad que establece la normativa europea «no es un requisito caprichoso, incomprensible y rígido, sino una prescripción justificada dirigida a que la trabajadora no se encuentre forzada a renunciar a su permiso de

${ }^{66}$ DOCE de 28 de noviembre de 1992, núm. 348. 
maternidad» (Ballester Pastor, 2019: 29). Tal y como ha señalado la doctrina, en principio, podría alegarse que el disfrute fraccionado de estas diez semanas constituye una mera posibilidad de la trabajadora, quien no pierde el derecho a disfrutar de la suspensión de manera continuada, de modo que la nueva previsión contemplada en el TRLET constituiría una mejora respecto de lo establecido en la Directiva. Sin embargo, al mismo tiempo, la doctrina pone de manifiesto que esta interpretación puede tener un «efecto perverso» consistente en que la trabajadora se vea obligada a reincorporarse a su puesto de trabajo y disfrutar del resto del permiso en las fechas más convenientes para la empresa, lo que, al fin y a la postre, acabaría desvirtuando la razón de ser del derecho de la trabajadora a fraccionar las diez semanas restantes (Ballester Pastor, 2019: 29; Cordero Gordillo, 2019: 12; Lousada Arochena, 2019: 6-7; Moreno Solana, 2019: 300-301; Pastor Martínez, 2019: 201).

Al mismo tiempo, la nueva regulación señala que, después de las primeras seis semanas inmediatamente posteriores al parto, la suspensión puede disfrutarse bien en régimen de jornada completa bien en régimen de jornada parcial, eso sí, previo acuerdo entre la empresa y la persona trabajadora, y conforme se determine reglamentariamente. Este último requerimiento, relativo al acuerdo entre la empresa y la persona trabajadora, resulta problemático. Por un lado, en relación con el disfrute de las diez semanas restantes en régimen de jornada completa, si se atiende al tenor literal del precepto, se requiere llegar a un acuerdo previo con la empresa, lo que plantea la duda de qué puede ocurrir si la empresa se niega a aceptarlo con base en razones fundadas y objetivas. Esta exigencia puede suponer un claro retroceso respecto de la anterior regulación y, además, dificultar la corresponsabilidad en el cuidado de los hijos (Moreno Solana, 2019: 304). Y, por otro lado, el previo acuerdo exigido entre la empresa y la persona trabajadora evidencia que la suspensión del contrato de trabajo a tiempo parcial por nacimiento constituye «una mera posibilidad condicionada al acuerdo con el empresario» (Ballester Pastor, 2019: 29 y Moreno Gené, 2020: 65). En este sentido, la reforma operada por el Real Decreto-Ley 6/2019 ha perdido la oportunidad de regular el disfrute de la suspensión del contrato de trabajo a tiempo parcial "como auténtico derecho de la persona trabajadora, siendo como es un instrumento importante de conciliación, y sin necesidad de que su disfrute dependiera de una negociación y acuerdo con la empresa» (Molina González-Pumariega, 2020: 19), medida que hubiera ayudado a promover, de manera más eficaz, la corresponsabilidad familiar.

El primer inciso del último párrafo del artículo 48.4 del TRLET dispone que

la persona trabajadora deberá comunicar a la empresa, con una antelación mínima de quince días, el ejercicio de este derecho en los términos establecidos, en su caso, en los convenios colectivos. 
Se trata de una norma general que afecta a todo el régimen jurídico de la suspensión del contrato por nacimiento, en virtud de la cual la persona trabajadora tiene el deber de preavisar a la empresa antes del comienzo de la suspensión acerca de cómo pretende configurar su disfrute, debiendo tener en cuenta, en su caso, la forma y las condiciones de comunicación establecidas a través de la negociación colectiva (Gorelli Hernández, 2019: 291). Además, debe recordarse que, si la persona trabajadora opta por el disfrute fraccionado, debe respetar nuevamente el preaviso de quince días a la hora de comunicar a la empresa el disfrute de cada periodo semanal o la acumulación de varios periodos semanales.

Pues bien, respecto de la regla general relativa al deber de preavisar, la norma no señala el momento concreto sobre el que debe preavisarse. En el caso de que la madre biológica decida adelantar el disfrute de la suspensión antes del parto, se entiende que debe avisar al empresario, como mínimo, quince días antes de comenzar el disfrute de dicho periodo. En el resto de los casos, la suspensión del contrato comenzará con el parto, ya que las primeras seis semanas deben disfrutarse inmediatamente después del mismo. En este supuesto concreto, en el que la suspensión del contrato se produce con el parto, ¿cuándo debe producirse el preaviso? Siguiendo la literalidad del precepto, se entiende que el preaviso debe realizarse, como mínimo, quince días antes del parto. Al respecto, aunque existe una fecha prevista de parto, debe tenerse presente que dicha fecha es una mera aproximación y que el parto puede producirse tanto antes como después de la misma. En este sentido, si se preavisa quince días antes de la fecha prevista de parto y, finalmente, el parto se retrasa, no habría ningún problema, ya que la persona trabajadora estaría cumpliendo el preaviso mínimo de quince días. Ahora bien, si el parto se adelanta, es probable que la persona trabajadora o bien no haya preavisado o bien lo haya hecho, pero con menos de quince días de antelación. Si se diera esta situación, se considera que el incumplimiento del preaviso mínimo de quince días no puede repercutir sobre el derecho a la suspensión, ya que «sería totalmente contrario a la finalidad de la misma retrasar el comienzo de la suspensión por falta de preaviso" y, además, contravendría el disfrute obligatorio de las primeras seis semanas inmediatamente posteriores al parto (Gorelli Hernández, 2019: 292).

En relación con los supuestos en los que los dos progenitores trabajen en la misma empresa y ejerzan el derecho a la suspensión por nacimiento, se establece en el segundo inciso del último párrafo del artículo 48.4 del TRLET que la dirección de la empresa puede limitar su ejercicio simultáneo por razones fundadas y objetivas que deberá motivar debidamente por escrito. Parece, pues, que «el legislador está protegiendo más la organización de la empresa que el derecho a la conciliación de la vida laboral y familiar» (Pérez Anaya, 2021: 17). Además, en esta ocasión también cabe percibir la falta de precisión en la redacción de la disposición. Así, el legislador se limita a contemplar, de manera genérica, la posibilidad que tiene la empresa de limitar el ejercicio simultáneo del derecho a la 
suspensión del contrato por nacimiento, sin delimitar el periodo concreto al que puede afectar tal limitación. A este respecto, ¿puede el empresario limitar el disfrute simultáneo del periodo en su integridad o se excluyen de tal limitación las seis semanas de disfrute obligatorio? Pues bien, teniendo en consideración que las seis semanas inmediatamente posteriores al parto tienen naturaleza obligatoria, se entiende que el empresario no puede impedir el disfrute simultáneo de las mismas, incluso cuando puedan existir objetivas razones empresariales (Gorelli Hernández, 2019: 292-293).

En suma, puede decirse que el Real Decreto-Ley 6/2019, de 1 de marzo, constituye una «norma importante», pero «la urgencia, la ausencia de debate y preparación parlamentaria, constituyen factores que explican su cuestionable calidad técnica» (Pastor Martínez, 2019: 189).

\section{A modo de conclusión}

A partir del análisis realizado, debe concluirse que la reforma operada por el Real Decreto-Ley 6/2019, de 1 de marzo, mediante la cual se ha equiparado el periodo de suspensión del contrato de trabajo de los dos progenitores por nacimiento de hijo/a, muestra la voluntad, tanto política como social, de avanzar hacia una corresponsabilidad real en el ámbito de las responsabilidades familiares. Así, mediante la asimilación del periodo de suspensión del contrato de trabajo de los dos progenitores, el establecimiento de un periodo obligatorio de suspensión del contrato para ambos y el carácter intransferible del derecho, se consiguen suplir algunas de las importantes carencias que venía presentando hasta ahora la normativa en la materia, cuyo impacto en el reparto de las responsabilidades familiares había sido claramente insuficiente. De ahí que, en principio, la nueva regulación de la suspensión del contrato por nacimiento merezca una valoración positiva.

Sin perjuicio de este reconocimiento inicial, lo cierto es que los vacíos jurídicos, las deficiencias técnicas y los problemas prácticos e interpretativos que se han ido poniendo de manifiesto a lo largo del análisis demuestran que la nueva norma no ha conseguido efectuar una reforma global de la materia, entre otras posibles razones, por su precipitada y acelerada elaboración. En este sentido, si bien la reforma supone un avance indiscutible en el camino hacia una corresponsabilidad más efectiva en la asunción de las responsabilidades familiares, lo cierto es que no resulta óptima para lograr la materialización de esta finalidad de manera eficaz. $\mathrm{Al}$ respecto, se considera que un tema de esta entidad exige una cuidada, minuciosa y completa regulación.

Como consecuencia de todo lo expuesto, serán necesarias próximas reformas de la normativa sociolaboral en esta materia para seguir progresando hacia una 
corresponsabilidad verdaderamente efectiva. En cualquier caso, en paralelo a los avances normativos, resulta imprescindible la implicación y el compromiso del conjunto de la sociedad en el camino hacia esta corresponsabilidad efectiva.

\section{Bibliografía}

Alonso Bravo, Milagros (2012). "La tutela del derecho de los trabajadores a no ser discriminados por razón de sus circunstancias familiares. Un mecanismo coherente para fomentar la corresponsabilidad entre hombres y mujeres en la asunción de responsabilidades familiares", Revista General de Derecho del Trabajo y de la Seguridad Social, núm. 28.

Arrieta Idiakez, Francisco Javier (2019). Bases para el estudio del Derecho del Trabajo. Madrid: Dykinson y la Academia Vasca de Derecho, 5. ${ }^{a}$ edición.

Ballester Pastor, María Amparo (2011). «La era de la corresponsabilidad: los nuevos retos de la política antidiscriminatoria», Lan harremanak: revista de relaciones laborales, núm. 25.

Ballester Pastor, María Amparo (2019). «El RDL 6/2019 para la garantía de la igualdad de trato y de oportunidades entre mujeres y hombres en el empleo y la ocupación: Dios y el diablo en la tierra del sol», Temas laborales: revista andaluza de trabajo y bienestar social, núm. 146.

Blázquez Agudo, Eva María (2017). «Más allá de la conciliación: hacia la corresponsabiliad», Femeris: Revista Multidisciplinar de Estudios de Género, núm. 2, vol. 2.

CÁmara Botía, Alberto (2012). «Medidas de conciliación de la vida personal y familiar con la laboral», Revista del Ministerio de Empleo y Seguridad Social, núm. 100.

Castellano Burguillo, Emilia (2007). «Funciones y alcance de las normas sobre conciliación de la vida laboral y familiar», Temas laborales: revista andaluza de trabajo y bienestar social, núm. 91.

Cordero Gordillo, Vanessa (2019). «La suspensión del contrato de trabajo por nacimiento de hijo o hija, adopción, guarda con fines de adopción y acogimiento tras el RDL 6/2019, de $1^{\circ}$ de marzo", Revista Internacional y Comparada de Relaciones Laborales y Derecho del empleo, núm. 3, vol. 7.

Fernández Collados, María Belén (2018). «Permiso por paternidad», en Sánchez Trigueros, Carmen (Dir.) y Hierro Hierro, Francisco Javier y Kahale Carrillo, Djamil Tony (Coords.). Un decenio de jurisprudencia laboral sobre la Ley de igualdad entre mujeres y hombres. Madrid: Boletín Oficial del Estado.

Gala Durán, Carolina (2017). «El permiso por paternidad: un balance tras casi diez años desde su implantación", Estudios financieros. Revista de trabajo y seguridad social: comentarios, casos prácticos, recursos humanos, núm. 406.

GoŃ SEIN, José Luis (2005). «La familia monoparental: la ausencia de atención política y legislativa y su impacto sobre la situación sociolaboral de la mujer», Temas Laborales: revista andaluza de trabajo y bienestar social, núm. 82.

Gorelli Hernández, Juan (2019). "Hacia la corresponsabilidad mediante la suspensión por nacimiento de hijos", Revista General de Derecho del Trabajo y de la Seguridad Social, núm. 53.

Gorelli Hernández, Juan (2020). "Tiempo de trabajo y conciliación de la vida laboral y familiar y personal: el RD-Ley 6/2019», González Ortega, Santiago (Coord.). El nuevo escenario en materia de tiempo de trabajo. XXXVIII Jornadas Universitarias Andaluzas de Derecho del Trabajo y Relaciones Laborales. Sevilla: Consejo Andaluz de Relaciones Laborales. 
Ispizua Dorna, Enea (2018). « ¿Hacia la equiparación de los permisos de maternidad y paternidad?», AAVV. Protección a la familia y Seguridad Social. Hacia un nuevo modelo de protección sociolaboral. Tomo I. Laborum: Murcia.

Llorens Espada, Julen (2017). "Nuevos retos de las prestaciones de la Seguridad Social por maternidad y paternidad", Lan harremanak; revista de relaciones laborales, núm. 38.

López Aniorte, María del Carmen (2000). «La suspensión del contrato de trabajo por maternidad biológica», Anales de Derecho: Universidad de Murcia, núm. 18.

López Aniorte, María del Carmen (2019). «Trabajadoras asalariadas y autónomas ante la protección por maternidad: la subsistencia de estereotipos sexistas en la ley y en la jurisprudencia», Revista Derecho Social y Empresa, núm. 10.

López López, Julia (2002). «Corresponsabilidad familiar y políticas legislativas sobre igualdad», Temas laborales: revista andaluza de trabajo y bienestar social, núm. 67.

Lousada Arochena, José Fernando (2019). «Maternidad y conciliación en el trabajo por cuenta ajena tras el Real Decreto-Ley 6/2019, de 1 de marzo: una primera aproximación», Revista Derecho Social y Empresa, núm. 11.

Mercader Uguina, Jesús R. (2017). «La creación por el Tribunal Supremo de la prestación por maternidad subrogada: a propósito de las SSTS de 25 de octubre de 2016 y de 16 de noviembre de 2016», Cuadernos de derecho transnacional, núm. 1, vol. 9.

Molina González-Pumariega, Rocío (2020). «Un paso más hacia la corresponsabilidad real: la suspensión del contrato de trabajo por nacimiento de hijo o hija, por adopción, guarda con fines de adopción y acogimiento tras el Real Decreto-ley 6/2019", Derecho Social y Empresa, núm. 12.

Molina Navarrete, Cristóbal (2009). «La «novela» sobre el permiso de paternidad: ¿acaso puede «hacerse el amor de padre» con el «desamor» de la ley?», Estudios financieros. Revista de trabajo y seguridad social: comentarios, casos prácticos, recursos humanos, núm. 321.

Molina Navarrete, Cristóbal (2021). «Permisos por nacimiento y recelo comunitario de acumularlos de acumularlos en la mujer: ¿y si elige ser familia monoparental? Comentario a la Sentencia del Tribunal de Justicia de la Unión Europea de 18 de noviembre de 2020, asunto C-463/19", Estudios financieros. Revista de trabajo y seguridad social: comentarios, casos prácticos, recursos humanos, núm. 454.

Monereo Pérez, José Luis y López Insua, Belén del Mar (2016). «La renovada tutela social de la maternidad en el marco de los derechos de conciliación", Revista General de Derecho del Trabajo y de la Seguridad Social, núm. 43.

Montoya Melgar, Alfredo (2018). Derecho del trabajo. Madrid: Tecnos, 39. a Edición.

Moreno Gené, Josep (2020). «De la suspensión del contrato por paternidad a la suspensión del contrato del otro progenitor por nacimiento de hijo: ¿un paso definitivo hacia la corresponsabilidad?, Nueva revista española de Derecho del Trabajo, núm. 227.

Moreno Solana, Amanda (2019). "La nueva regulación de la maternidad y la paternidad: nacimiento, cuidado de menor y corresponsabilidad en el cuidado del lactante en el RDL 6/2019, de 1 de marzo", en De la Puebla Pinilla, Ana y Mercader Uguina, Jesús R. (Dirs.). Tiempo de reformas: en busca de la competitividad empresarial y de la cohesión social. Valencia: Tirant lo Blanch.

Nieto Rojas, Patricia (2018). «La intransferibilidad de los permisos de paternidad como elemento básico para la corresponsabilidad. La recepción nacional de la propuesta de Directiva de permisos parentales», en AAVV. Protección a la familia y Seguridad Social. Hacia un nuevo modelo de protección sociolaboral. Tomo I. Laborum: Murcia. 
Palomino Saurina, Pilar (2021). "Incompatibilidad entre el permiso por nacimiento de un hijo y la suspensión del contrato por nacimiento", Diario La Ley, núm. 9817, edición digital.

Pastor Martínez, Albert (2019). «Las medidas laborales del Real Decreto-Ley 6/2019, de 1 de marzo de medidas urgentes para garantía de la igualdad de trato y de oportunidades entre mujeres y hombres en el empleo y la ocupación: un paso hacia la efectividad de la igualdad de trato y de oportunidades desde la corresponsabilidad», Iuslabor, núm. 1.

Pérez Anaya, Rosa María (2021). «La suspensión del contrato de trabajo por nacimiento y por adopción o acogimiento: un paso decisivo hacia la corresponsabilidad», Trabajo y derecho: nueva revista de actualidad y relaciones laborales, núm. 76, edición digital.

Pérez Guardo, Rocío y Serrano Serrano, Natalia (2012). «¿Responde el diseño de los permisos de maternidad y paternidad en España al presupuesto de corresponsabilidad entre hombres y mujeres?», Acciones e investigaciones sociales, núm. 33.

Pérez Guerrero, María Luisa (2021). «Familias monoparentales: ¿es la regulación de la prestación y el permiso por nacimiento discriminatoria con las mujeres trabajadoras», Blog Trabajo, Persona, Derecho y Mercado. Nuevos retos del mercado laboral: pobreza en el trabajo, economía colaborativa y envejecimiento, en http: //grupo.us.es/ iwpr/2021/03/15/familias-monoparentales-es-la-regulacion-de-la-prestacion-y-el-permiso-por-nacimiento-discriminatoria-con-las-mujeres-trabajadoras/ (última consulta: 4 de junio de 2021).

Prieto Padín, Patricia (2021). Las excedencias familiares y el trabajo. Cizur Menor: Thomson Reuters Aranzadi.

Quintanilla Navarro, Raquel Yolanda (2017). «Teletrabajo y conciliación de la vida personal, familiar y laboral», Revista del Ministerio de Empleo y Seguridad Social, núm. 133.

Rodríguez Escanciano, Susana (2005). «La protección jurídico-laboral de la maternidad: algunas cuestiones pendientes», Temas laborales: revista andaluza de trabajo y bienestar social, núm. 82 .

Rodríguez Pastor, Guillermo Emilio (2018). «El permiso y la prestación por paternidad en el contexto social actual y futuro", en AAVV. Protección a la familia y Seguridad Social. Hacia un nuevo modelo de protección sociolaboral. Tomo II. Laborum: Murcia. 